\title{
DIE PRAKTIESE SY VAN DIE PREDIKING
}

Weleerwaarde Voorsitter en Broeders!

Die onderwerp wat ons vanmôre kortliks met mekaar wil bespreek, kan op verskillende maniere geformuleer word, en tog sal ons wesenlik altyd dieselfde moet sê, al sê ons dit dan met ' $n$ ander aksent en betekeniskleur. Dit is so, omdat die prediking nooit werklik en waarlik prediking is nie, indien dit nie altyd vasgeanker is aan die praktyk nie, dws. as dit nie self 'n stuk praktyk is nie.

Die prediking is soos 'n seilskip wat van sy tuisland af uitvaar no 'n ver bestemming. Indien dit die binding met die verlede, met die land van sy herkoms verbreek, dan is dit soos 'n skip sonder 'n vlag. Hierdie soort skip hys alleen die vlag wat by omstandighede pos. Dit is in werklikheid nêrens tuis nie. Almal, selfs diegene wat dit skynbaar verwelkom, wantrou dit. Sy enigste werklike tuiste is sy hede, die golwe waarop dit vaar. Die ken-merkende teken, die vlag, is slegs skyn. Uiteindelik gaan dit dan ook naamloos onder in die golwe van die hede wat as enigste ware werklikheid getel het. Hierdie soort prediking verval in die heillose, ruggraatlose opportunisme van die hede. I.p.v. prediking is dit toespraak. Dit is so, 
omdat sy symbolum slegs skyn is. Hierdie prediking is net praktyk, en daarom geen prediking meer nie.

Dieselfde geld van die skip wat geen egte bestemming het nie. Netsoos die eerste soort word dit sonder roer, ,"deur elke wind van lering heenen-weer gewaai" (Ef. 4 vers 14). Die egte prediking word nie alleen in die regte rigting gehou deur die perfectum van die heilsgebeure van die koms van Jezus Christus nie, maar ook deur die futurum van Sy toe-koms dws. deur die groot eskatalogiese gebeure aan die einde van die dae met Sy wederkoms. Die prediking, die hele kerklike lewe, trouens die hele huidige wêreldgeskiedenis is soos 'n snaar gespan tussen die afsluiting van die eenmalige heilsgebeure in Jesus Christus, nl. Sy Hemelvaart en, aan die ander kant: Sy Wederkoms.

Maar om terug te keer na ons eerste beeld: 'n Skip het nie net 'n land van herkoms en 'n bepaalde bestemming nie, maar is alleen op sy plek op die see. 'n Skip is van weinig nut in die woestyn. Dit kan op droë land hoogstens in 'n museum tuis wees. Dieselfde geld van die tipe prediking wat nie reken met die gedurig-bewegende, voortdurend-veranderlike omstandighede van die praktyk rondom ons nie. Dit mag wel as kuriositeit of geskiedenis waarde besit, maar sal nooit soos die goedgemikte pyl sy doel tref nie. Ons moet nie soos Jona die gevaarsone van die praktyk probeer ontvlug nie, hetsy die Nineve van 'n gewone groot stad waarin ons gemeente mag lê, hetsy die magtige bouwerk van hedendaagse filosofie of ideologie. Jona het die wêreld in vakke opgedeel en gemeen dat God net in sommige afdelings teenwoordig is. Die Christendom ken nie 'n aparte God vir Son-dag en 'n aparte God vir Maandag soos die Germane nie. Daar is vir die christelike geloof ook geen God wat tot die Kerk en die kring van Kerk en Prediking beperk is, en daarnaas nog 'n god-lose praktyk waar God nie ter sprake kom, of, nog beter gesê: Waar God nie self Sy Woord spreek nie. Jesus Christus het ook nie mens geword êrens op 'n idilliese, poëtiese eiland van liefde en vrede nie, maar het midde in ons sondige bestaan en wêreld ingekom. Die ewige Woord het ook nie 'n neutrale, sondelose... ons kan byna sê: on-praktiese . . liggaam aangeneem nie. Dit is 'n dosetiese dwaling. Die ewige Woord, Jesus Christus het "sarks", sondige vlees GEWORD. Wat van die ewige Woord gesê kan word, kan in hierdie verband ook sonder voorbehoud van die gepredikte Woord gesê word. Ons moet in die prediking altyd hierdie tipiese struktuur van die inkarnasie vashou, nl. dat Gods Woord, Christus, midde in ons sondige wêreld ingekom het; dat die gepredikte Woord dieselfde moet doen in navolging van Hom wat eerste was.

Dit het tot dusver geblyk dat die prediking vasgeanker is aan 'n verlede (die land van sy herkoms), aan 'n hede (die aktualiteit van die hier-ennou) en aan 'n toekoms (die Wederkoms van Jesus Christus). In hierdie verband wil ons nou die volgende sê: Aldrie hierdie wesenlike momente van die prediking is tegelykertyd 'n stuk harde praktyk. Ons spreek dan eerstens oor: 
1. Die Praktyk van de Prediking se Perfectum. Dit was veral die Reformatore wat groot nadruk op hierdie praxis van die perfectum (soos dit vir ons in die Oue en Nuwe Testament beskrywe is) gelê het. Vir hulle was die dinge en gebeure wat in die Bybel beskrywe is, geen abstrakte idee of idilliese poësie van 'n ver land van nêrens nie, of die dialektiese beweging van die absolute Gees (soos die Hegelse dosetisme later wou nie) maar konkrete realiteit, harde praktyk. Die Reformatore het besef dat die hele christelike geloof staan en val met die handhawing, of nie-handhawing van hierdie praxis ... dat daar geen dodeliker vyand van die Christendom is as die skyn, as die dosetisme nie. Daar is die merkwaardige geskiedenis van Matt. 28 vers $11-15$ waar aan ons vertel word dat die owerpriesters, nadat aan hulle vertel is, alles wat gebeur het (praxis, realiteit), hulle aan die soldate geld gegee het om te sê: ,Sy disiepels het in die nag gekom en Hom gesteel terwyl ons aan die slaap was." U sien die bedoeling van die owerpriesters. Hulle wil voorgee dat hier die gebeure slegs skyn is. Tereg vertaal die Afrikaanse vertaling verder: „En hierdie storie is onder die Jode versprei tot vandag toe." Teenoor hierdie storie klink die blye, konkrete klank van die Evangelie: Die Heer het waarlik opgestaan. Hierdie waarlik druk nie soseer 'n gnoseologiese waarheid uit, as wat dit die werklikheid, die realiteit, die praktyk van hierdie heilsgebeurtenis, van hierdie heilsfeit benadruk nie. 'n Prediking wat nie met hierdie harde feitelikheid, hierdie konkrete praktyk van die perfectum reken nie, dié is nog Bybels, nog reformatories. Geen kunsgrepe van allegorie, metodisme, persoonlikheidsbeklemtoning, geen storie of fyn verhaalkuns sal hierdie dinge (indien dit in die prediking verwaarloos word) ooit reg kan maak nie. Die prediking moet gedurig daarop heenwys dat daar iets gebeur het, werklik gebeur het, dat God 'n daad gedoen het - skepping, belofte, geboorte, lyding, kruisiging, sterwe, opstanding, hemelvaart - en dat deur die realiteit van hierdie gebeure die wêreld wesenlik, waarlik, werklik verander het, en nooit meer sy alledaagse, natuurlike gang kan gaan of sin en betekenis kan hê nie.

'n Tweede feit wat die reformatorie in hierdie verband reg raakgesien het, is dat ons nooit aan die perfectum van hierdie praktyk moet gaan torring nie. Niks wat ons by hierdie perfectum kan byvoeg (bv. ons Kerk, ons vroomheid, ons redelikheid e.s.m.) kan vergoed wanneer ons die eenmaligheid van die heilsgebeure in Jesus Christus te kort gedoen het nie. Daar kan nooit 'n plus-teken by hierdie Perfectum bykom nie. Die hedendaagse teologie druk hierdie feit uit met die woord "Einmaligkeit"; die reformatore het die woord sola gebruik bv. sola fide, sola gratia, sola scriptura. Hierdie sola is eksklusief, dit sluit ons menslike plus uit. Dit is nie alleen 'n grammatikale of temporele (historiese) perfectum nie, maar ook 'n kwalitatiewe perfectum in die sin van die perfektheid, die volkomenheid van die heilswerk van God in Christus Jesus.

Maar nou is dit nie so dat hierdie bybelse perfectum vir die reformatore tot ' $n$ versteende praktyk verstar het nie. Dit is, deur die Testimonium Spiritus Sancti, 'n lewende perfectum wat sy krag ook in die praktyk 
van die hier-en-die-nou voelbaar laat word. Of, anders gesê: Daardie perfectum, daardie feit beteken altyd iets, en hierdie betekenis geld altyd vir die praktyk van die hier-en-die-nou. Daar is by die reformatore 'n verset teen alle ontologiese en of skolastiese spekulasies ... dit gaan vir hulle om die praktiese sin en betekenis van die Evangelie in hulle prediking. Weeren-weer vra bv. die Heidelbergse Kategismus: Was für nutz bekommen wir aus erkandtnuss der schöpffung und fürsehung Gottes? Was nutz bekomestu auss der heiligen empfengnuss und geburt Christi. Was nutzet uns die Aufferstehung Christi? ens. ens. Hierdie Perfectum is dus geen filosfiese absoluutheid of konstante nie, maat werk soos 'n suurdeeg op beslissende en dringende wyse deur in die lewe van ons wat hier-en-nou leef. WeRnle het Calvyn bv. verwyt dat hy in sy teologie nie 'n objektiewe verslag op wetenskaplike wyse gee van wie Christus was en wat $\mathrm{Hy}$ gedoen het nie, maar dat CALvyn alleen maar die skoon, stigtelike gedagtes van 'n prediker aan ons verkondig. Hierdie verwyt is in dié sin saaklik dat dit vir CAlvyn nie om ontologie gegaan het nie, maar om Teologie, Praktiese Teologie en Verkondiging.

'n Mens kan bv. allerlei diepsinnige filosofiese spekulasies voordra wanneer jy iets wil sê aangaande die alomteenwoordigheid van God. Ons kan bv. sê dat 'n alomteenwoordige wese so moet wees dat dit in alle ruimtelike dinge moet wees en alle leë ruimte moet vul, selfs die oneindig groot ruimtes tussen die sterre en sonnestelsels. Maar dit is nie wat die Bybel onder die alomteenwoordigheid van God verstaan nie . . . en in die reformatoriese teologie gaan dit juis primêr om die Bybelse prediking. Die Bybel bedoel met die alomteenwoordigheid van God iets heel prakties en nugter en daarom iets heel troosvol nl. Wáár ek my ookal mag bevind, God is dáár; en Hy is daar om te help en te troos, in watter ver alleenheid of droewige of gevaarlike omstandighede ek ookal is.

So kan bv. allerlei diepsinnige en interessante vrae gevra word oor Gods Alwetendheid bv. as Hy geweet het van die sondeval, waarom het $\mathrm{Hy}$, die Almagtige wat ons liefhet, dit nie verhoed nie? Dit is egter menslike metafisika wat moontlikhede of liewer onwerklikhede ontleed en teen mekaar opweeg. Wat prakties van heilsinteresse is, is dat God altyd weet wat ons nood en omstandighede is, altyd ons gebede hoor en van ons ellende weet en ons daaruit sal verlos en daarin sal bystaan.

Daar kan bv. fyn ontologiese spekulasies wees oor die Triniteit bv. die uitgaan van die Heilige Gees van die Vader en van die Seun. Die nugtere, praktiese sin van hierdie heilsfeit is egter dat God wat uitgaan, ,gaat ergens heen. In dit geval naar uw wankel hart"' (VAN Selms).

Die Bybel beskryf nie poëties-romanties en op treurige wyse die feit van die geopende graf van Jesus Christis nie. Die Bybel is hier heel nugter, heel prakties. Tereg sê CALvyn dat Christus se geopende graf vir ons die opening van die deur tot die ewige lewe is.

Dit is hierdie praktiese realiteit van die perfectrum wat in ons prediking moet deurklink. Ons moet nie met allerlei tegniese terme en handig- 
hede of omhaal van woorde ons nie-verstaan van die sin van die heilsfeite probeer verberg nie. Maar dit stel natuurlik geweldig swaar eise aan die prediker. Hy moet weer-enmeer besef dat die Bybel in 'n vreemde taal en tegelykertyd in die taal van 'n vé tyd, van Gods tyd, geskrywe is. Hy moet altyd weer worstel totdat die eeue wat tussen die preasens van sy prediking en die perfectum van die heilsgebeure duur en deursigtig word. Dit noem ons eksegese - eksegese uit die grondtale, soos die reformatore dit ook wou hê. Prakties en eenvoudig gesê: Ons kan nooit goed spreek sonder 'n Kittel- en Nestle-bybel, twee goeie woordeboeke en 'n goeie atlas van die heilige land in ons hand nie, Maar dit bring ons alreeds dadelik by:

2. Die Praktyk van die Prediking se Preasens, dws. die praktiese voorbereiding, wording en lewering van die preek.

Laat ons begin deur hier iets oor die tekskeuse te sê: Daar bestaan onder ons predikante veral drie maniere van die kies van 'n teks:

(i) Somtyds kry ons tussen ons sogenaamde praktiese werksaamhede deur, tog 'n geleentheid om te dink, bv. in ons motorkar laat saans op pad terug huis toe van 'n laat vergadering of van huisbesoek af. Ongelukkig gaan motorbestuur en Bybellees nie saam nie, en tog voel ons dan lus om 'n preek te maak, selfs 'n treffende preek. Ons dink dan ook 'n paar pakkende godsdienstige gedagtes uit. Tuisgekom, eet ons, lees ons ons koerant en gaan dan gewoonlik slaap. Partykeer kry ons onder die lees van die koerant nog ' $n$ ingewing of twee, gewoonlik 'n baie praktiese ingewing uit die nasionale of internasionale politiek of nuusberigte. Lateraan, gewoonlik Saterdagaand, begin ons dan die Bybel deurblaai vir 'n passende (of, soos die koerantberigte i.v.m. huwelike dit stel) 'n bypassende teks. Kry ons 'n sodanige teks, dan is ons tevrede. Kry ons dit nie ... wel ... dan des te slegter vir die teks, aangesien die preek mos dan al klaar gemaak is. Ons kan hierdie metode die post mortem metode noem. Enigiemand wat iets van die reformatoriese teologie af weet, sal insien dat hier niks reformatories in te vinde is nie. In hierdie metode van tekskeuse kom daar niks van grondige uitleg-kunde, grondige eksegese ter sprake nie.

Daar is maar een plek om 'n preek te maak. Nie in ons motorkar nie, ook nie in ons sitkamer nie (dikwels terwyl ons daar koerantlees en na die radio luister) maar in ons studeerkamer met ons Bybel, Gesangeboek en ander hulpboeke baie naby byderhand.

(ii) Daar bestaan nog ' $n$ tweede wyse van tekskeuse. U ken die bekende grappie van die man en sy hond: Die hond is, so vertel hy, te oulik. As hy sê: ,,kom!' dan kom die hond, of hy kom nie. Ongelukkig is dit ook 'n wyse van tekskeuse onder ons predikante. Ons vind op 'n goeie dag (of, is dit ' $n$ kwaaie dag?) uit dat al ons kispreke gedaan is. Miskien was hulle al lankal gedaan, nie in die kwantitatiewe sin van die woord nie, maar in kwalitatiewe sin. Dan begin ons naarstiglik soek na 'n ,nuwe" teks vir 'n ,nuwe" preek. Dan vind ons dit, of ons vind dit nie. As ons dit vind, is dit gewoonlik van die "treffende" of „mooi" tipe tekse. 
Ons moeilikheid is hier, dat ons, soos die Bybel dit self sê, vergaan vanweë 'n gebrek aan kennis ... en hier is nog nie teologiese kennis bedoel nie, maar slegs deeglike, grondige Bybelkennis... kennis van die Bybelse geskiedenis, van die inhoud van die Bybel.

Geen goeie advokaat sal aan 'n junior, wat nie die wetboeke van voor tot agter ken nie, opdra om in 'n lewensbelangrike regsaak die regspunte te soek nie. En in die preek gaan dit om meer as 'n lewensbelangrike saak; dit gaan naamlik om die ewige lewe en ewige dood. U sal sê dat in die geval van die regsaak die regter baie meer krities is as die gemeente wat gewoonlik uit gewone mense bestaan. Daar word egter vergeet dat daar, terwyl daar tot hierdie gewone alledaagse mense gespreek word, daar tegelykertyd gespreek word voor die aangesig van die heilige God. En hierdie laaste is eintlik die eerste en die belangrikste. Wie die ontsettende nabyheid van hierdie feit in elke preek onthou, sal nooit in gemaklike alledaagsheid verval nie. Ons doel met die prediking moet nie wees om mense te paai en te behaag nie, maar om die eer van God te soek. Ons moet in die eerste plek nie reken om die instemming van die gemeente nie. Gewoonlik is hulle oordeel esteties: „Dominee het vandag mooi gepreek." Ons moet egter op grondige wyse Gods Woord aan hulle bring. Hierdie laaste is altyd 'n waagstuk, 'n groot verantwoordelikheid. Hierdie verantwoordelikheid word alreeds aanvaar met ons tekskeuse. Ons kan bygevolg ook nie hierdie tweede metode van tekskeuse, die metode van probeer-en-tref gebruik nie.

Die psigologie het i.v.m. hierdie werkwyse een groot feit aangetoon, nl. dat dit veral hier (by hierdie twee wyses van tekskeuse) is, dat daar die groot gevaar van herhaling, van die terugkeer van 'n paar stereotipe lieflingsgedagtes en bygevolg van die een-tonigheid en verveling geleë is. Laat ons dit duidelik maak met verwysing na 'n ander lewensgebied: 'n Kunsskilder wat alleen maar sy eie klein omgewing ken, of die abstrakte kunstenaar wat gedurig deur maar put uit die klein ervaring van 'n klein ruimte en lewe, se werke vertoon 'n star eentonigheid... gedurigdeur weer die terugkeer van een en dieselfde temas, een en dieselfde motiewe, kleurskakeringe, rangskikking en vorme. Die gevaar is dat die kunstenaar dit self naderhand nie eers meer merk nie, want die vervalwees in 'n groef vernou 'n mens se gesigspunt sodanig, dat jy later selfs nie eers meer die inklemming in die groef raksien nie. Die kunstenaar egter wat baie deur ons land reis, wat baie moeite doen om oral in hierdie wye en mooi land van ons iets in te neem en te leer, se werk is altyd verfrissend en vars, soms verrassend in perspektief en uitvoering en toon 'n definitiewe ontwikkeling in die rigting van rypwording.

(iii). Hierdie opmerking bring ons alreeds by die derde en regte wyse van tekskeuse. Die voorwaarde is hier dat ons tuis moet wees in die gebied wat ons moet ondersoek, tuis in die Bybelgeskiedenis en in die Bybelinhoud, nie net in gedeeltetjies daarvan nie, maar in die hele wye veld en volle diepte van die rykdom daarvan. Ons moet hier nie wees soos die arme kunstenaar wat na stof soek nie. Hierdie derde soort man word deur 
die stof self gedring, is so deurdring daarvan dat hy weet dat sy lewe gans te kort is om ooit alles te vertolk. Dan sal ons nie tekse soek nie, maar dan sal die tekse sig aan ons opdring in 'n kaledoskopiese veelheid van feit en patroon. Die waarheid is dan dat ons nie 'n teks kies nie, maar dat die teks sigself kies, of anders gesê: dat die teks ons aangryp. Hiervoor is nodig dat ons die Bybel een, twee of selfs driekeer per jaar van voor tot agter deur sal lees... nie soos 'n hoender mieliepitte oppik nie, maar letterlik: van-voor-tot-agter. Indien daar êrens sprake is van ,sistematiese teologie", dan is dit hier. Het U al daaraan gedink dat as u maar een bladsy per dag lees u byna 400 bladsye per jaar sal deurlees? Ons kan dit maar in die mooi Afrikaanse Vertaling lees. Belangrike hulpmiddels is hier eerstens die potlood vir kanttekeninge, onderstrepings ens. Tweedens: Ander vertalings bv. Engels, Duits en Hollands. In elkeen van hierdie vertalings sit alreeds 'n groot stuk eksegese, sit in elk geval prikkelende verskille van bewoording, idioom en segging. Dit kos inspanning en wilskrag om dieselfde geskiedenis in drie of vier tale weer-en-weer te herlees. Dit kos nog meer wilskrag om dit elke dag gereeld te doen. Dit :s die deurgevoerde volgehoue sistematiek waarvan ons hierbo gepraat het. Daar is tereg gesê dat poësie maar een persent inspirasie is en 99 persent harde, eerlike werk. Dieselfde kan ons netso van toepassing maak op ons tekskeuse.

Dit vra natuurlik baie persoonlike dissipliene en voorbereiding. Ons sal elke dag vir hierdie lees en vir die maak van ons preke 'n uur of twee moet afsonder; en ons sal ons streng aan hierdie program moet hou. Miskien sal die beste tyd hiervoor die rustigheid van die laat-aand wees. Maar behalwe hierdie uiterlike strengheid moet daar ook 'n geestelike voorbereiding vir hierdie taak (en ook vir die lew'ering tan die preek) wees. Dit is so 'n fyn en byna-breekbaar teer saak dat 'n mens huiwer om daaroor te praat. Laat ek, wat oor die hele gebied geld, in die vorm van 'n vraag oor 'n klein gebied van die praktyk van die prediking stel: Hoeveel van ons kom nie geestelik onvoorbereid op die kansel nie? al is ons preek ens. dan ook mooi uitgewerk. Het ons die nodige frisheid en geestelike voorbereidheid en toerusting wat alleen deur gebed en geestelike rus verkry kan word? In die formulier vir die bevestiging van ouderlinge word gesê dat hulle hulle gedurigdeur moet oefen in die oordenking van die verborgenhede van die geloof. Dit is ook vir ons predikante woord-vir-woord waar.

Daar is egter ook nog ander hulpmiddels wat nie slegs vir ons tekskeuse nie, maar ook vir die werklike maak van die preek baie belangrik is.

1. ' $n$ Woordeboek van plek- en persoonsname. Rondom elkeen van hierdie name is daar 'n stuk heilsgeskiedenis geweef wat by die noem van so 'n naam weer voor ons kan opleef soos herinneringe uit sy kinderdae vir 'n ou mens.

2. Aanvullend hierby is ' $n$ historiese en geografiese atlas van die heilige land waarmee ons in die gedagte die afstande, ligging en landskap van ons teksvers na kan loop. 
3. Dan is daar ook nodig 'n baie goeie Bybelkonkordans. Hierdeur kan ons die samehang en betekenisskakering van ' $n$ bepaal Je begrip en gegewenheid opbou, om nie 'n meganiese veelheid en gebrokenheid van 'n begrip (bv. Lig) voor ons te hê nie, maar 'n organies eenheid daarvan.

4. Laastens wil ons hier noem 'n N.T.-se, O.T.-se u'oordeboek soos dié van G. Kitrel. Dit is byna onmisbaar.

Hierdie werke is egter geen towerboeke wat nou op magiese wyse pragtige preke by ons na vore sal roep nie. Die maak van 'n preek bly altyd 'n worsteling met die Woord en die stof moet altyd persoonlik deurleef en toegeëien word. Hierdie boeke is alleen maar baie belangrike hulpmiddels, en iemand wat dit nalaat, kan vergelyk word met 'n boer wat 'n groot en goeie saaiplaas met net een enkele skoffelpik wil bewerk. Hy sal dit nie kan doen nie, al het hy ook 'n Universiteitsgraad in Landbou, of hy sal genoodsaak wees om met 'n ander man se kalwers te ploeg. Die vraag is egter of ons nie miskien te veel van ander mense se kalwers, van 'n ander mense se preekbundels gebruik maak nie. Natuurlik is dit goed om ander se preke te lees; dit is veral hier by ons goed omdat ons so min geleentheid kry om na 'n preek te luister. Maar hierdie preke moet krities gelees en benut word. Alleen wanneer 'n gedagte volkome toegeëien en in ons eie denkpatroon ingeweef is, mag ons dit gebruik.

Maar met hierdie opmerking het ons alreeds by die punt van die tekskeuse verbygestoot en op die wye veld van die maak van 'n preek gekom. Die eerste vereiste is hier dat ons die hoofbegrippe van ons teks asook die teks in sy totaliteit op analietiese wyse noukeurig sal ontleed en sodoende sal probeer begryp. Maar tegelykertyd sal ons ook weer hierdie begrippe in hulle onderlinge teksverband asook in die wyere samehang van hoofstukke en bybelhoek op sintetiese wyse saam moet voeg. Tereg het $V_{\text {AN }}$ Selms in hierdie verband opgemerk, ,Waarheid en waarde van die Godswoord lê nie soseer in die oorgelewerde woord self nie, as in die verhouding tot die mense en toestande waartoe en waarin hierdie woorde vir die eerste keer gepreek is nie. Vandaar dat die godswoorde, losgemaak van hulle omgewing, mekaar skynbaar teespreek."

Met hierdie feit dat die waarheid nie in 'n woord of begrip as sodanig lê nie, maar in 'n verhouding, sal ons baie goed rekening moet hou. Ons sal ons moet inspan om na die beste van ons vermoë die taal van daardie vér en vreemde tyd te verstaan. J. Arundel Chapman het in „The Theology of Karl Barth" eenkeer gesê...,,There is a strange new world in the Bible, and by it Barth is haunted. It has become the soul of his teology." Ook in ons prediking moet ons gedurigdeur worstel om gelyktydig te word met hierdie ,strange new world in the Bible."

Maar as dit waar is van die perfectum van die Bybel dat „,die waarheid nie soseer in die oorgelewerde woord self geleë is nie, as in die verhouding tot die mense en toestande waartoe en waarin dit vir die eerste keer gespreek is," dan is dit netso waar van die Praesens van die Prediking. In die prediking is dit nie net noodsaaklik dat die prediker die perfectum van die 
prediking sal probeer verstaan nie, maar ook dat hy daardie perfectum sal verstaan in die preasens van sy eie tyd en situasie. Die „so het die Here gespreek" van die Bybel, moet altyd weer in die prediking word tot „so spreek die Here".

Hierdie vertaling, hierdie transponering op die hede, vereis eerstens dat ons 'n oop oog vir ons tyd en vir die nood van ons tyd sal hê. Dit beteken dat ons, behalwe die intieme kennis van die omstandighede en behoeftes van elke huisgesin, ook op hoogte sal moet wees met die gebeurtenisse oor die hele wêreld en ook van ons eie land. Verder ook met die huidige wysgerige en ideologiese strominge en bv. met die moderne poësie. In laasgenoemde lê dikwels baie wysbegeerte en wysheid opgesluit, al is dit alleen maar wat Paulus in 1 Kor. 1 en 11, ,die wysheid van woorde" noem.

Maar ook hierdie saak van allerlei geestesstrominge van ons tyd, moet ons in die regte perspektief sien. Ons moet nie gaan dink dat ons tyd met ons wysbegeerte en ideologië nou sonder meer die tyd van die verkondiging is, bevoorreg bo alle ander tye en eeue nie. Koopmans het in „De Tien Geboden" hierdie saak suiwer gesien toe hy gesê het, „het is te menschelijk, te berekenend gedacht, wanneer wij meenen, dat in zulke tijden de conjunctuur voor het Evangelie gunstig is. $\mathrm{Er}$ is niet alleen geen aanknopingspunt in den mensch, er is ook geen aanknopingspunt in den tijd. Het aanknopingspunt voor Gods Evangelie is Gods Wet ..."

Maar juis daarom - omdat Gods Woord loodreg van bo af in ons tyd en lewe inslaan en sy eie aanknopingspunt skep, omdat die Gees van God soos die wind waai en ons sy waarheen en waarvandaan nie ken nie daarom ,kunnen wij niets in ons zelven machteloos achten. Niet onze natuur, noch onze cultuur. De Bijbel doet dat ook niet." (VAN DER LeEUW).

Tussen die pole van hierdie dialektiek moet ons ons opdrag met wakker oplettendheid uitvoer. Dit wil natuurlik nie sê dat ons religieuse joernalistiek moet bedryf of met ons holruggeryde stokperdjies in die kerkgebou en in die harte van die gemeentelede moet probeer inry nie. Aan die ander kant moet ons ook nie in niksseggende, verstarde ,cliches" praat nie. Ons moet in die taal van ons tyd praat, omdat hierdie tyd ook Gods tyd kan wees. Om dit in die taal van die diakensformulier te sê: Ons moet met oplettendheid en versigtigheid die woord voer soos dit hier-en-nou nodig is. Dit moet by ons nie gaan oor die tydsontwrigting in die algemeen en oor duistere sinspelinge op vereniginge en wêreldgebeure nie, maar oor die feit van: ,Jy is die man."

Die lewering van die preek moet probeer om uit te munt in duidelikheid. Daar moet altyd 'n logiese helderheid van samehang en opbou wees. Die voordrag moet helder wees en veral nie geaffekteerd en kunsmatig nie.

Soos die kerkgebou die ruimtelike omraming van die hele erediens is, so is die musiek en lied die klankvolle omlysting van die diens van die Woord. Hierdie omlysting moet by die prediking pas; die skildery en die 
raam moet ' $\mathrm{n}$ eenheid vorm, anders skaad die een die ander. Die voorlees van die psalms en die gesange moet helder wees, ook wat die sin daarvan betref. Die skemerlig van die verborge God sal wel by die sing daarvan tot sy reg kom.

Die prediking moet altyd plaasvind onder die besef dat daar hieren-nou 'n geweldige iets gebeur, werklik gebeur nl. dat God hier-en-nou teenwoordig is. Onder die besef van hierdie teenwoordigheid, hierdie reële, konkrete teenwoordigheid van die lewende God, moet ons erediens gebeur. In hierdie erediens moet ons die Woord verkondig van Hom wat hier-en-nou teenwoordig is en nou na ons luister. Ons moet altyd op die kansel gaan onder die besef dat daar hier-en-nou iets gebeur, waarlik en werklik gebeur tussen God en ons, tussen ons en God ... Dit dan is die praktyk van ons prediking as preasens.

3. Maar die praktyk van die prediking is ook baie nou verbonde met 'n bepaalde futurum, met die verlangende uitsien na Sy toe-koms. Dit wil aan ons sê dat die tyd waarin ons leef geen spanninglose, neutrale tyd is nie, maar 'n hooggelaaide, gekwalifiseerde tyd. Dit is gespanne omdat dit uitryk na Sy wederkoms, omdat Sy wederkoms die toekoms van ons tyd is.

Dit het groot gevolge vir ons lewe en daarom tegelyk vir ons prediking. Indien $\mathrm{Hy}$ nie weer sou kom om te oordeel die lewende en die dode nie, sou alle tye gelyk wees en sou elkeen kon doen wat hy wou. Dan sou ons enigste toekoms en die laaste woord oor ons lewe die Niks, die Dood wees. Die enigste etiese reëls sou dan dié wees om die lewe tussen geboorte en dood so lekker en so gelukkig as moontlik te reël.

Maar nou bely die Christelike Kerk dat die lewe veel meer is as net 'n lekker, gelukkige bestaan tussen geboorte en dood. Anders gesê: Die Christelike Kerk bely dat Jesus Christus aan die einde van die dae na ons toe sal kom „om elkeen te vergeld volgens sy dade." (Matt. 16:27). Dit kwalifiseer ons tyd en lê 'n groot verantwoordelikheid op ons teenoor God m.b.t. die sinvolle besteding van heel ons lewe. Omdat Hy aan die einde van die dae na ons toe kom, daarom kan ons nie leef soos ons wil nie, maar word ons opgeroep om in geloof uit dankbaarheid ons lewe in te rig volgens Sy Woord en Wet. Hierdie groot verantwoordelikheid in die lig van die komende gerig is die appélgrond vir ons prediking. Maar ons preek die Evangelie, die goeie boodskap. Dit wil o.a. ook sê dat $\mathrm{Hy}$ wat aan die einde kom om te rig, ons Here Jesus Christus is. Albei, gerig en vryspraak, moet in een saamverbind wees in ons prediking.

Maar wat vir ons in hierdie verband van die futurum van die prediking belangrik is, is die dringende, spanningsvolle karakter wat ons lewe en prediking kry uit die werklikheid van Sy wederkoms.

Hierdie realisme is vir die erns van ons prediking meer werd as al ons moontlike en onmoontlike kunsgrepe van gemaakte erns, trane, geaffekteerde spraak ens. Dit is 'n heilsame praktyk, hierdie realisme, omdat dit die praktyk van die heil self is.

Universiteit van Pretoria.

B. I. ENGELBRECHT. 